\title{
CARACTERIZAÇÃO DE UMA JUNTA SOLDADA DE AÇO INOXIDÁVEL DUPLEX PELO PROCESSO TIG NA RAIZ E ENCHIMENTO COM PROCESSO MIG-MAG *
}

\author{
André de Albuquerque Vicente ${ }^{1}$ \\ Débora Arruda Cabral ${ }^{2}$ \\ Alexandre Bueno ${ }^{3}$ \\ Thiago Viana de Oliveira Turra ${ }^{4}$ \\ Tiago Felipe de Abreu Santos ${ }^{5}$ \\ Jorge Alberto Soares Tenório ${ }^{6}$
}

\begin{abstract}
Resumo
Os aços inoxidáveis duplex caracterizam-se por apresentarem microestrutura bifásica, ferrítica-austenítica. A fração volumétrica ideal das fases é $50 \%$ de ferrita e $50 \%$ de austenita, entretanto, essa condição é de difícil obtenção quando realiza-se a união por soldagem a arco desses materiais. Neste trabalho estudou-se as melhores práticas de soldagem do aço inoxidável duplex UNS S31803 garantindo a obtenção de frações volumétricas ideais de ferrita e austenita. Foi soldado um corpo de prova pelos processos TIG e MIG-MAG. Para esse corpo de prova foi realizada a soldagem de um passe de raiz e um passe de reforço através do processo TIG e o preenchimento da junta através do processo MIG-MAG. Foram realizados os seguintes ensaios no corpo de prova: micrografia (metal base, ZAC face, ZAC raiz, face da Zona Fundida e raiz da Zona Fundida), medição da fração volumétrica de ferrita, microdureza Vickers (HV500), ensaio de tração da junta soldada, dobramento guiado, Charpy e ensaio de corrosão por pitting.
\end{abstract}

Palavras-chave: Aços Inoxidáveis Duplex; Soldagem; TIG; MIG.

\section{CHARACTERIZATION OF A DUPLEX STAINLESS STEEL JOINT WELDED BY TIG PROCESS IN ROOT AND FILLING WITH MIG-MAG PROCESS}

\section{Abstract}

Duplex stainless steels are characterized by their biphasic, ferritic-austenitic microstructure. The ideal volumetric fraction of the phases is $50 \%$ of ferrite and $50 \%$ of austenite, however, this condition is difficult to obtain when arc welding these materials. In this work, the best welding practices to the duplex stainless steel UNS S31803 were studied, guaranteeing the ideal volumetric fractions of ferrite and austenite. A test joint using both TIG and MIG-MAG processes was welded. For this test piece, a root pass and a reinforcement pass were welded through the TIG process and the filling of the joint through the MIG-MAG process. The following tests were carried out on the specimen: micrograph (base metal, HAZ face, HAZ root, face of the molten zone and root of the molten zone), measurement of ferrite volumetric fraction, Vickers microhardness (HV500), tensile test, guided folding, Charpy and corrosion by pitting test.

Keywords: Duplex Stainless Steels; Welding; TIG; MIG.

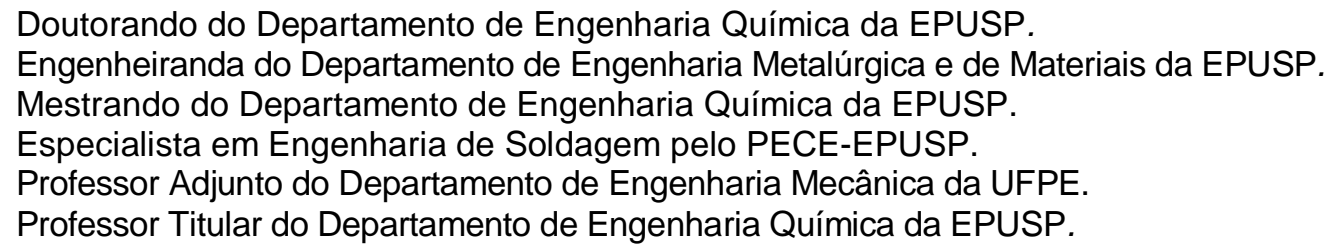




\section{INTRODUÇÃO}

Os aços inoxidáveis duplex são ligas baseadas no sistema $\mathrm{Fe}-\mathrm{Cr}-\mathrm{Ni}-\mathrm{Mo}-\mathrm{N}$. As composições químicas usuais destes aços são: 18,5 a 27\% Cr; 4 a $8 \%$ Ni; 2 a 4\% Mo; C menor que $0,08 \%$ e também podem conter $\mathrm{Cu}$ e $\mathrm{W}$. Os aços inoxidáveis duplex apresentam uma microestrutura bifásica ferrítica-austenitica com frações volumétricas de cada uma das fases ferrite e austenita aproximadamente iguais a $50 \%$. Estes aços apresentam boa resistência à corrosão sob tensão e alta resistência à corrosão intergranular, características estas devidas à fase ferrita. $A$ fase austenita proporciona excelentes propriedades mecânicas e boa soldabilidade. Estas propriedades são consequência do balanço microestrutural das fases austenita e ferrita que se pode obter pelo controle da composição química e do processamento termomecânico ao qual a liga é submetida. [1-16]

A adição de elementos formadores e estabilizadores da austenita como, por exemplo o nitrogênio, promove a obtenção de uma microestrutura duplex à temperatura ambiente. As propriedades mecânicas dos aços inoxidáveis duplex são superiores àquelas dos aços inoxidáveis comuns. Os limites de escoamento dos aços inoxidáveis duplex são duas vezes os dos aços inoxidáveis ferríticos e austeníticos que apresentem resistência à corrosão por pitting semelhantes. [1-16]

$\mathrm{Na}$ soldagem a microestrutura dos materiais da região da junta soldada varia desde a poça de fusão até a ZAC como consequência da história térmica (ciclos térmicos e repartição térmica) experimentada nesta região. A microestrutura final depende da velocidade de resfriamento a partir de cada temperatura máxima presente na repartição térmica. [3-5, 8-11]

A maioria dos aços inoxidáveis duplex possuem uma relação de $\mathrm{Cr}$ e $\mathrm{Ni}$ equivalente acima de dois $\left(\mathrm{Cr}_{e q} / \mathrm{Ni}_{\text {eq }}>2\right)$, dessa forma solidificam preferencialmente como ferrita $(\delta)$, em temperaturas próximas de $1450^{\circ} \mathrm{C}$. A microestrutura permanece ferrítica até atingir a linha "solvus" da ferrita. Durante o resfriamento as composições químicas da ferrita e austenita são alteradas continuamente. A solubilidade do nitrogênio na ferrita é muito baixa, o que obriga um controle maior sobre a taxa de resfriamento de forma que durante o resfriamento do cordão de solda, possa existir a formação adequada de austenita para dissolver o nitrogênio em excesso, evitando a precipitação de nitreto de Cromo. Já no estado sólido, ocorre a precipitação de austenita em temperaturas menores que as da linha "solvus" da ferrita. [1-4, 8-11, 14]

Nos aços inoxidáveis duplex a presença de duas fases pode dificultar que estas fases sejam mantidas pelo efeito dos ciclos térmicos de soldagem. Nos ciclos térmicos, a temperatura varia desde a zona de fusão onde ocorrem as transformações de fases durante a solidificação até o metal adjacente à solda na zona afetada pelo calor onde ocorrem transformações no estado sólido. Desta forma cuidados específicos devem ser tomados para a soldagem de aços inoxidáveis duplex para se obter uma microestrutura ferrítica-austenítica com frações volumétrica das fases próxima de $50 \%$. Deve-se evitar também a precipitação de fases deletérias. $[4,9,14,16]$

As propriedades da solda dependem da composição química, do procedimento e processo de soldagem e das frações volumétricas de austenita e ferrita na microestrutura. Esta fração volumétrica pode ser ajustada pela alteração da composição química e pelo controle da temperatura durante a soldagem. O principal desafio na Soldagem a arco dos aços inoxidáveis duplex é manter as excelentes 
propriedades mecânicas e a resistência à corrosão na zona fundida (ZF) e na zona afetada pelo calor (ZAC).

Dependendo da velocidade de resfriamento e do tempo de manutenção em determinadas faixas de temperatura, pode ocorrer a precipitação de outras fases, além da ferrita e da austenita, levando à fragilização destes aços. A fragilização dos aços inoxidáveis duplex pode ser dividida em dois grupos: fragilização de baixa temperatura e fragilização de alta temperatura. A fragilização de baixa temperatura normalmente acontece numa faixa de temperatura de $300^{\circ} \mathrm{C}$ a $500^{\circ} \mathrm{C}$, onde ocorre a precipitação da fase alfa' ( $\left.\alpha^{\prime}\right)$, chamada fragilização de $475^{\circ} \mathrm{C}$. Geralmente está associada à utilização do equipamento em serviço e, desta forma, limita a temperatura máxima de aplicação dos aços inoxidáveis duplex abaixo de $280^{\circ} \mathrm{C}$. A fragilização de alta temperatura ocorre na faixa de temperatura de $600^{\circ} \mathrm{C}$ a $1000^{\circ} \mathrm{C}$, onde precipitam diversas fases intermetálicas como as fases sigma $(\sigma)$, chi $(\chi)$, carbonetos $\left(\mathrm{M}_{23} \mathrm{C}_{6}\right)$ e nitretos de cromo $\left(\mathrm{Cr}_{2} \mathrm{~N}\right)$. Este tipo de fragilização pode ocorrer durante a soldagem ou o tratamento térmico pós-soldagem. $[4,9,14,16]$

As principais fases que podem precipitar e influenciar de forma significativa as propriedades dos aços inoxidáveis duplex e super duplex são: os carbonetos do tipo $\mathrm{M}_{23} \mathrm{C}_{6}$, a fase sigma $(\sigma)$, a fase alfa' $(\alpha$ ) e os nitretos de cromo, entre outros. A fase sigma $(\sigma)$ é uma fase intermetálica com um reticulado tetragonal, extremamente dura, não magnética e causa fragilização quando precipitada no material. $A$ fase sigma começa a precipitação nas interfaces ferrita-austenita e seus principais constituintes são o cromo e o molibdênio. A precipitação dessa fase sigma, empobrece a matriz ferrítica nos seus contornos de grãos, retirando os elementos cromo e molibdênio que são justamente os agentes que promovem a resistência à corrosão. $[4,9,14,16]$

Os carbonetos do tipo $\mathrm{M}_{23} \mathrm{C}_{6}$ normalmente aparecem nos aços inoxidáveis duplex com alto teor de cromo. A fase alfa' (ferrita secundária), ocorre normalmente entre $300^{\circ} \mathrm{C}$ e $550^{\circ} \mathrm{C}$. As precipitações intermetálicas podem ser iniciadas a partir de temperaturas aproximadas de $570^{\circ} \mathrm{C}$, tendo uma intensificação na faixa de $800^{\circ} \mathrm{C}$ a $850^{\circ}$ C. (16)

A figura 1 apresenta o efeito de alguns elementos de liga na formação de alguns precipitados. 


\section{Temperatura $\left[{ }^{\circ} \mathrm{C}\right]$}

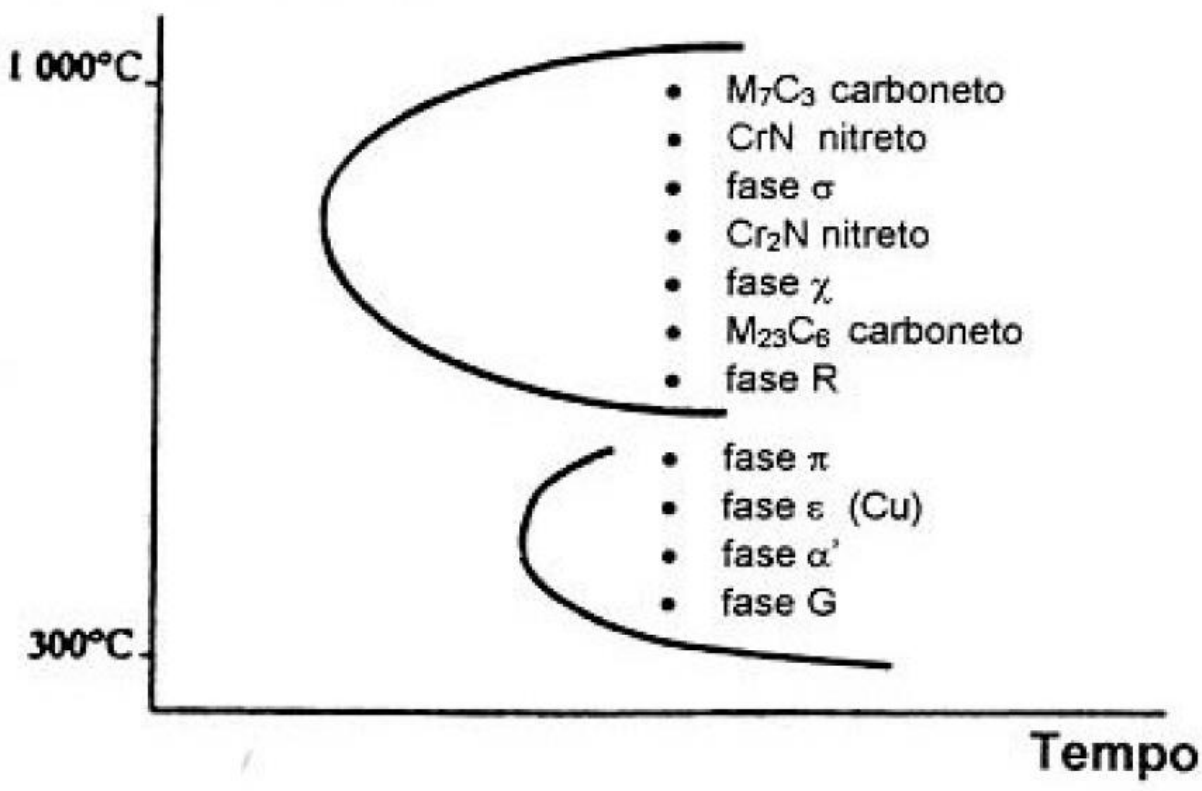

Figura 1 - Efeito de alguns elementos de liga na formação de alguns precipitados [16]

Para obter-se juntas com microestrutura bifásica e frações volumétricas das fases ferrita e austenita próximas a 50\%, deve-se controlar a velocidade de resfriamento da junta soldada. A figura 2 apresenta de forma bastante didática os resultados obtidos em uma junta soldada submetida a diferentes velocidades de resfriamento. Observa-se que o resfriamento muito rápido leva à precipitação de nitretos de cromo do tipo $\mathrm{Cr}_{2} \mathrm{~N}$ devido à fração volumétrica de ferrita ficar muito elevada (azul). Por outro lado, o resfriamento muito lento leva à precipitação de fases deletérias. Observa-se, particularmente, a precipitação de fase sigma $(\sigma)$ (vermelho). Uma parametrização adequada do processo de soldagem leva a uma velocidade de resfriamento ótima da junta soldada, obtendo-se frações volumétricas de ferrita e austenita próximas a 50\% e evitando a precipitação de fases deletérias (amarelo). [9]

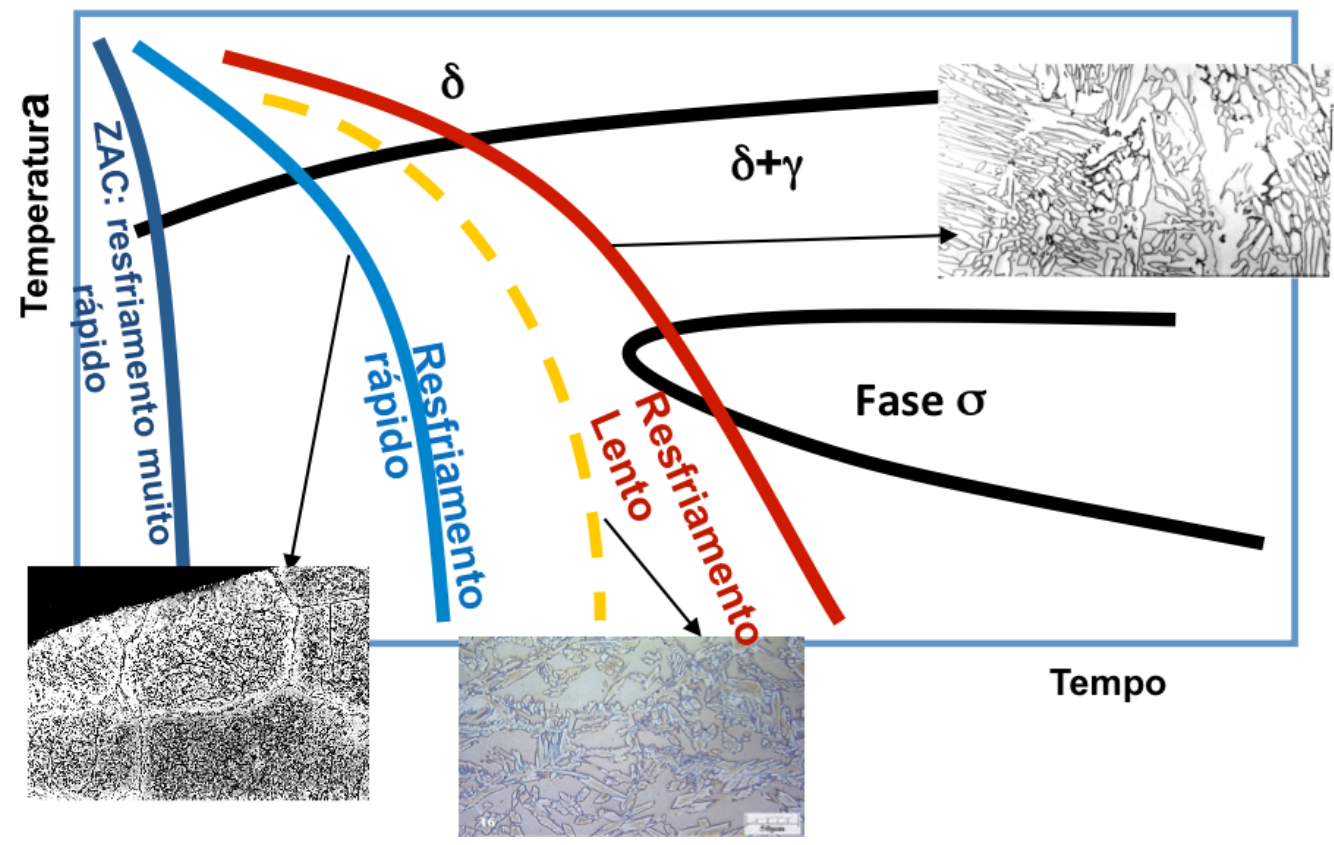


Figura 2 - Curva de resfriamento contínuo destacando-se os efeitos da taxa de resfriamento sobre as precipitações de fases deletérias. [9]

\section{MATERIAIS E MÉTODOS}

A matéria prima utilizada nesse trabalho foi o metal de base duplex UNS S31803, com espessura de $16,00 \mathrm{~mm}$. Foram cortadas duas chapas nas medidas de $220 \mathrm{x}$ $300 \times 16,0 \mathrm{~mm}$.

Utilizou-se o arame ER 2209 conforme AWS 5.9 para preenchimento da junta nas seguintes dimensões: $2,00 \mathrm{~mm}$ para TIG e 1,2mm para MIG.

Para o processo TIG foi utilizado como gás de proteção uma mistura gasosa contendo $98 \%$ de $\mathrm{Ar}+2 \%$ de $\mathrm{N}_{2}$. Já no processo MIG, a mistura usada foi $98 \% \mathrm{Ar}+$ $2 \% \mathrm{O}_{2}$.

Os chanfros foram preparados conforme AWS Welding Handbook.

Para realização da soldagem do corpo de prova e para o controle das variáveis e do processo de soldagem foram utilizados, um fluxômetro da marca Carbografite para conferência da vazão do gás de proteção, um regulador de pressão Modelo 300FL, um Termômetro infravermelho modelo Fluke 62 mini digital para controle de temperatura inicial e interpasse, um Alicate Amperímetro Minipa ET 3388 para conferência de corrente e tensão, um Transferidor de grau em aço modelo Protractor NO-5001 para conferência do ângulo do bisel e o tempo de soldagem foi medido através de cronometro.

A figura 3 apresenta o croqui da junta soldada:

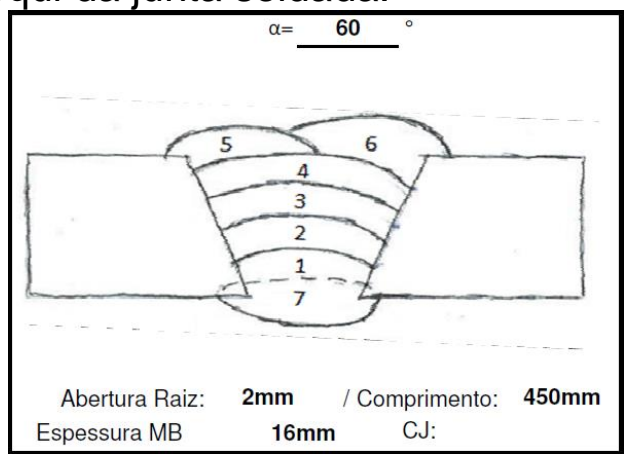

Figura 3 - Croqui da junta soldada indicando os passes de 1 a 7 .

Processo TIG: passes 1, 2 e 7. Processo MIG: passes 3, 4, 5 e 6.

Para a avaliação microestrutural da junta, foram realizadas micrografias do corpo de prova nas seguintes regiões: metal de base, ZAC da face, ZAC da raiz, face da ZF e raiz da ZF. Foi utilizado o programa "AnalySIS" para a realização da contagem de ferrita e austenita. As amostras foram atacadas eletroliticamente em solução de $\mathrm{NaOH} 20 \%, 6 \mathrm{~V}$, por 90 segundos. As micrografias foram feitas com aumento de 400X.

Foram realizados ensaios de microdureza Vickers (HV500) na amostra previamente submetida ao ataque eletrolítico.

Realizou-se ensaio de tração da junta soldada. A preparação da junta foi feita conforme ASME IX QW - 462.1 (a), o método utilizado para a realização seguiu a QW - 152 onde foram confeccionados dois corpos de prova com espessura média de $16 \mathrm{~mm}$ e largura média de $19,1 \mathrm{~mm}$, aplicando-se uma carga para causar a ruptura, tendo como critério de aceitação a QW - 153. [17]

Para o teste de dobramento guiado, seguiu-se a QW - 462.2 com dimensões $10 \times 16 \times 200 \mathrm{~mm}$ em um ângulo de 180ㅜ, o Ø do cutelo foi de $40 \mathrm{~mm}$ e distância entre 
roletes de 63mm, o método de ensaio baseou-se na $\mathrm{QW}$ - 162 e o critério de aceitação foi em conformidade a QW 163. [17]

Realizou-se ensaio Charpy, onde foram analisadas duas regiões distintas da junta soldada. Uma foi na zona fundida e a outra na linha de fusão, com três corpos de provas para cada região (totalizando seis CPs). A dimensão dos CPs foi $10 \times 10 \times 55 \mathrm{~mm}$, onde foram averiguadas a energia absorvida pelo material $(\mathrm{J})$ e a expansão lateral $(\mathrm{mm})$. O ensaio foi realizado a $-46^{\circ} \mathrm{C}$.

O ensaio de corrosão foi realizado mantendo um corpo de prova (dimensões 14,3x25x48mm e massa 132,5619gr) em solução (Cloreto Férrico) durante 24 horas a uma temperatura controlada de $40^{\circ} \mathrm{C}$, onde o preparativo foi de acordo com a norma ASTM G 48 - 03 Método A [18], com a metodologia de ensaio em conformidade as normas Petrobras N-133 [19] e NORSOK M-601 [20].

\section{RESULTADOS E DISCUSSÃO}

\subsection{Soldagem da Junta}

A tabela 1 indica os parâmetros de soldagem utilizados para confecção da junta soldada. Iniciou-se a soldagem pelo passe de raiz (passe1) e sequencialmente um passe de reforço (passe 2), ambos através do processo TIG. Os passes de enchimento foram através do processo MIG-MAG (passes 3, 4, 5 e 6). Finalmente, a raiz foi parcialmente removida e realizou-se um último passe de acabamento da raiz através do processo TIG (passe 7).

Tabela 1 - Parâmetros de soldagem do corpo de prova.

\begin{tabular}{|c|c|c|c|c|c|c|c|c|c|c|c|}
\hline $\begin{array}{l}\text { Classe } \\
\text { AwS }\end{array}$ & $\begin{array}{c}\text { Temp. Inic. } \\
\left({ }^{\circ} \mathrm{C}\right)\end{array}$ & \begin{tabular}{|c|} 
Passe \\
$\mathbf{N}^{\circ}$ \\
\end{tabular} & \begin{tabular}{|c|}
$\begin{array}{c}\text { Camada } \\
\mathrm{N}^{\circ}\end{array}$ \\
\end{tabular} & $\begin{array}{c}\emptyset \\
(\mathrm{mm})\end{array}$ & $\begin{array}{c}\text { Tensão } \\
\text { (V) }\end{array}$ & \begin{tabular}{|c|}
$\begin{array}{c}\text { Corrente } \\
\text { (A) }\end{array}$ \\
\end{tabular} & \begin{tabular}{|c|}
$\begin{array}{c}\text { Vazão Gás } \\
(1 / \text { min })\end{array}$ \\
\end{tabular} & $\begin{array}{c}\begin{array}{c}\text { V. Arame } \\
(\mathrm{m} / \mathrm{min})\end{array} \\
\end{array}$ & $\begin{array}{l}\text { Tempo } \\
\text { Solda } \\
\end{array}$ & \begin{tabular}{|c|}
$\begin{array}{c}\text { Vel. Soldagem } \\
(\mathrm{mm} / \mathrm{min})\end{array}$ \\
\end{tabular} & $\begin{array}{c}\begin{array}{c}\text { Heat Imput } \\
(\mathrm{kJ} / \mathrm{min})\end{array} \\
\end{array}$ \\
\hline ER 2209 & $\leq 150^{\circ} \mathrm{C}$ & 1 & 1 & 2 & 13 & 130 & 12 & $\mathrm{x}$ & 00:08:50 & 51 & 1,99 \\
\hline ER 2209 & $\leq 150^{\circ} \mathrm{C}$ & 2 & 2 & 2 & 13 & 130 & 12 & $\mathrm{x}$ & 00:10:01 & 45 & 2,26 \\
\hline ER 2209 & $\leq 150^{\circ} \mathrm{C}$ & 3 & 3 & 1,2 & 18,5 & 117 & 18 & 3,4 & 00:05:45 & 78 & 1,66 \\
\hline ER 2209 & $\leq 150^{\circ} \mathrm{C}$ & 4 & 4 & 1,2 & 18,7 & 120 & 18 & 3,4 & 00:06:17 & 72 & 1,88 \\
\hline ER 2209 & $\leq 150^{\circ} \mathrm{C}$ & 5 & 5 & 1,2 & 18,7 & 120 & 18 & 3,4 & $00: 04: 13$ & 107 & 1,26 \\
\hline ER 2209 & $\leq 150^{\circ} \mathrm{C}$ & 6 & 5 & 1,2 & 18,7 & 115 & 18 & 3,4 & 00:04:15 & 106 & 1,22 \\
\hline ER 2209 & $\leq 150^{\circ} \mathrm{C}$ & 7 & 1 & 2 & 13 & 130 & 12 & $x$ & 00:09:50 & 46 & 2,22 \\
\hline
\end{tabular}

\subsection{Análise Microestrutural}

O critério de aceitação adotado foi a ausência de fases deletérias e frações volumétricas de ferrita e austenita próximas a $50 \%$ em metalografia óptica com 400 $X$ de aumento. A fração volumétrica de ferrita deverá estar ente 35 e $65 \%$. Os resultados obtidos foram satisfatórios.

A figura 4 apresenta as cinco regiões da junta onde realizaram-se as análises microestruturais.

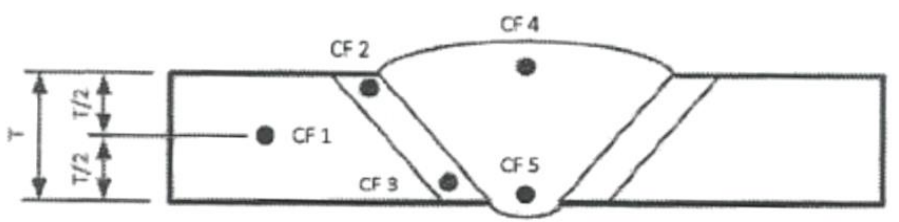

Figura 4- Regiões da junta soldada onde realizaram-se as análises microestruturais.

A figura 5 apresenta as micrografias obtidas nas 5 regiões estudadas: 

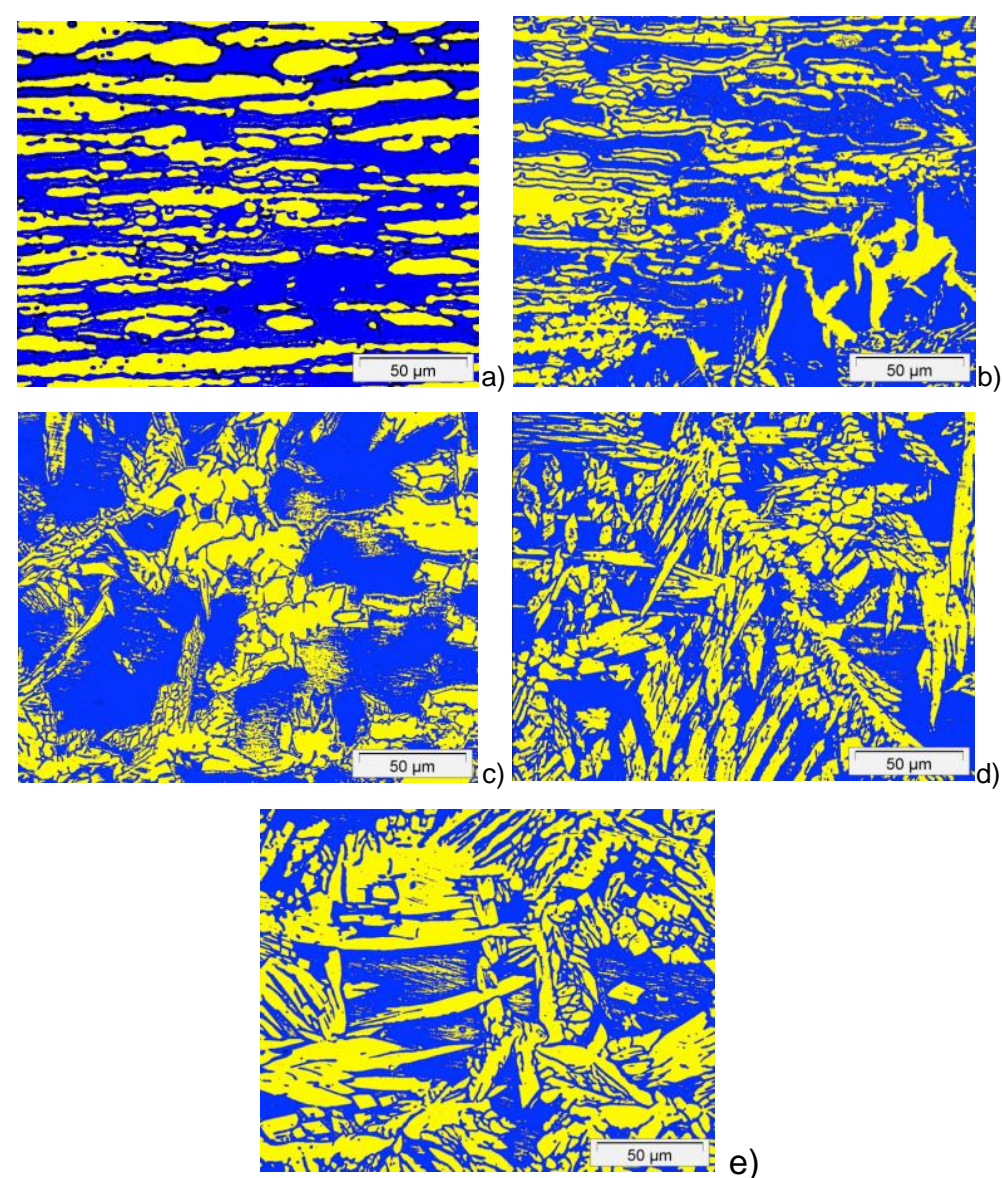

Figura 5 - Micrografias das regiões da junta soldada onde realizou-se análise microestrutural. a) Metal Base (CF1), b) ZAC face (CF2), c) ZAC raiz (CF3), d) ZF face (CF4), e) ZF raiz (CF5). Ataque eletrolítico, $\mathrm{NaOH} 20 \%, 6 \mathrm{~V}, 90 \mathrm{~s}$.

A tabela 2 apresenta as frações volumétricas de ferrita nas regiões estudadas.

Tabela 2 - Frações volumétricas de ferrita das regiões da junta soldada onde realizou-se análise microestrutural.

\begin{tabular}{|c|c|c|}
\hline Identificação & Análise de Contagem de Ferrita (\%) & Resultado \\
\hline Metal de Base & 65 & Aprovado \\
\hline ZAC - Face & 52 & Aprovado \\
\hline ZAC - Raiz & 42 & Aprovado \\
\hline Solda - Face & 43 & Aprovado \\
\hline Solda - Raiz & 51 & Aprovado \\
\hline
\end{tabular}

\subsection{Microdureza Vickers (HV500)}

De acordo com os critérios adotados, os valores obtidos foram satisfatórios pois ficaram entre 20 e 25 Vickers.

A figura 6 apresenta as regiões da junta onde realizaram-se as análises de microdureza Vickers (HV500). 


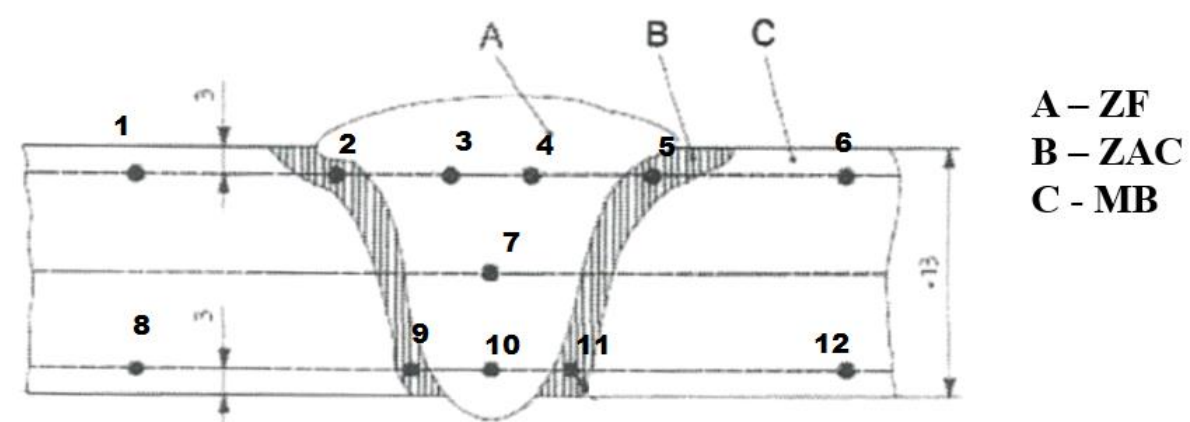

Figura 6 - Regiões da junta soldada onde realizaram-se as análises de microdureza Vickers.

A tabela 3 apresenta as os valores de microdureza Vickers (HV500) das 12 regiões estudadas.

Tabela 3 - Microdureza Vickers (HV500) das 12 regiões estudadas.

\begin{tabular}{|c|c|c|c|c|c|c|c|c|c|c|c|}
\hline \multicolumn{10}{|c|}{ Microdureza Vickers (HV00) } \\
\hline M. Base & ZAC & \multicolumn{2}{|c|}{ Solda } & ZAC & M. Base & Solda & M. Base & ZAC & Solda & ZAC & M. Base \\
\hline $\mathbf{1}$ & $\mathbf{2}$ & $\mathbf{3}$ & $\mathbf{4}$ & $\mathbf{5}$ & $\mathbf{6}$ & $\mathbf{7}$ & $\mathbf{8}$ & $\mathbf{9}$ & $\mathbf{1 0}$ & $\mathbf{1 1}$ & $\mathbf{1 2}$ \\
\hline 21 & 21 & 20 & 22 & 21 & 20 & 25 & 20 & 20 & 23 & 20 & 20 \\
\hline
\end{tabular}

\subsection{Ensaio de Tração}

A ruptura dos corpos de provas aconteceu no metal base, Os valores de limites de resistência à tração foram $755 \mathrm{MPa}$ no CP 1 e $764 \mathrm{MPa}$ no CP 2. Com isso, diante do limite de resistência mínimo especificado em 620MPa a junta soldada teve suas propriedades mecânicas.

A tabela 4 apresenta os resultados obtidos no ensaio de tração para os 2 corpos de prova ensaiados.

Tabela 4 - Ensaios de tração.

\begin{tabular}{|c|c|c|c|c|c|c|c|}
\hline Identificação & Espessura (mm) & Largura (mm) & Área (mm $\mathbf{~}^{2}$ & Carga Máxima (N) & Limite de Resistência a Tração (MPa) & Local de Ruptura & Situação \\
\hline CP 1 & 16,2 & 19,2 & 311,04 & 234750 & 755 & Metal Base & Aprovado \\
\hline CP 2 & 16,1 & 19,1 & 307,51 & 234940 & 764 & Metal Base & Aprovado \\
\hline
\end{tabular}

\subsection{Dobramento Guiado}

Realizou-se ensaio de dobramento guiado em 4 corpos de prova. Não houve descontinuidades após o término do ensaio sendo a junta, portanto, aprovada. A tabela 5 apresenta os resultados dos testes de dobramento guiado.

Tabela 5 - Testes de dobramento guiado.

\begin{tabular}{|c|c|c|c|c||}
\hline Identificação & Dimensões (mm) & Ângulo & Identificação e dimensões das descontinuidades detectadas & Situação \\
\hline $\mathrm{CP} 1$ & $10 \times 16 \times 200$ & $180^{\circ}$ & Isento de descontinuidades & Aprovado \\
\hline $\mathrm{CP} 2$ & $11 \times 16 \times 200$ & $180^{\circ}$ & Isento de descontinuidades & Aprovado \\
\hline $\mathrm{CP} 3$ & $12 \times 16 \times 200$ & $180^{\circ}$ & Isento de descontinuidades & Aprovado \\
\hline $\mathrm{CP} 4$ & $13 \times 16 \times 200$ & $180^{\circ}$ & Isento de descontinuidades & Aprovado \\
\hline
\end{tabular}

\subsection{Ensaio Charpy a $-46^{\circ} \mathrm{C}$}

Foram analisadas duas regiões, com três corpos de prova cada. $\mathrm{O}$ critério de aceitação foi de no mínimo $27 \mathrm{~J}$ de energia absorvida e $0,38 \mathrm{~mm}$ no mínimo de expansão lateral.

A primeira região (zona fundida a $1,5 \mathrm{~mm}$ da face) teve uma média de energia absorvida de $76 \mathrm{~J}$ e uma expansão lateral média de $0,62 \mathrm{~mm}$, sendo assim aprovada de acordo com o critério de aceitação. A segunda região analisada (a 1,5 mm da 
superfície da linha de fusão) também teve resultados acima do mínimo estabelecido no critério de aceitação, com média de energia absorvida em $192 \mathrm{~J}$ e expansão lateral com média de $1,71 \mathrm{~mm}$.

A figura 7 apresenta as regiões da junta de onde retirou-se os corpos de prova para o ensaio Charpy a $-46^{\circ} \mathrm{C}$.

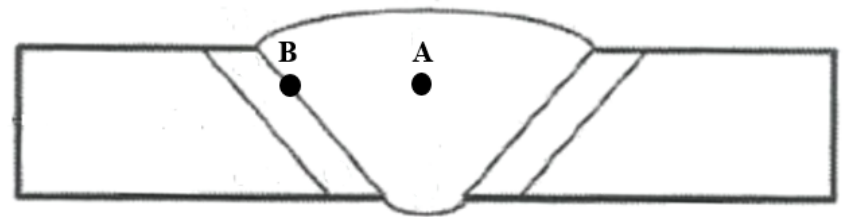

$$
\begin{aligned}
& A-Z F: C 1, C 2 \text { e C3 } \\
& \text { B-LF: C4, C5 e C6 }
\end{aligned}
$$

Figura 7 - Regiões da junta de onde retirou-se os corpos de prova para o ensaio Charpy a $-46^{\circ} \mathbf{C}$.

A tabela 6 apresenta os resultados dos corpos de prova do ensaio Charpy a $-46^{\circ} \mathrm{C}$.

\begin{tabular}{|c|c|c|c|c|c|c|c|}
\hline \multirow{2}{*}{ Dimensões (mm) } & \multirow{2}{*}{ Temperatura de Ensaio $\left({ }^{\circ} \mathrm{C}\right)$} & \multirow{2}{*}{ Localização } & \multicolumn{4}{|c|}{ Energia Absorvida (J) } & \multirow{2}{*}{ Situação } \\
\hline & & & $\mathrm{C1}$ & $\mathrm{C2}$ & $\mathrm{C3}$ & Média & \\
\hline \multirow{4}{*}{$10 \times 15 \times 55$} & \multirow{4}{*}{-46} & \multirow{4}{*}{$\begin{array}{l}\text { Solda } \\
\text { a } 1,5 \mathrm{~mm} \text { da superfície }\end{array}$} & 67 & 77 & 84 & 76 & \multirow{4}{*}{ Aprovado } \\
\hline & & & \multicolumn{4}{|c|}{ Expansão Lateral (mm) } & \\
\hline & & & \begin{tabular}{|l|}
$\mathrm{C} 1$ \\
\end{tabular} & $\mathrm{C} 2$ & C3 & Média & \\
\hline & & & 0,58 & 0,68 & 0,61 & 0,62 & \\
\hline & & & & & & & \\
\hline \multirow{2}{*}{ Dimensões (mm) } & \multirow{2}{*}{ Temperatura de Ensaio $\left({ }^{\circ} \mathrm{C}\right)$} & \multirow{2}{*}{ Localização } & \multicolumn{4}{|c|}{ Energia Absorvida (J) } & \multirow{2}{*}{ Situação } \\
\hline & & & $\mathrm{C4}$ & $\mathbf{C 5}$ & C6 & Média & \\
\hline \multirow{4}{*}{$10 \times 15 \times 55$} & \multirow{4}{*}{-46} & \multirow{4}{*}{$\begin{array}{l}\text { Linha de fusão } \\
\text { a } 1,5 \mathrm{~mm} \text { da superfície }\end{array}$} & 200 & 192 & 183 & 192 & \multirow{4}{*}{ Aprovado } \\
\hline & & & \multicolumn{4}{|c|}{ Expansão Lateral (mm) } & \\
\hline & & & C1 & $\mathrm{C2}$ & $\mathrm{C3}$ & Média & \\
\hline & & & 1,81 & 1,65 & 1,67 & 1,71 & \\
\hline
\end{tabular}

Tabela 6 - Ensaio Charpy a $-46^{\circ} \mathrm{C}$

\subsection{Corrosão por Pitting - ASTM G48 A}

O critério para esse ensaio foi de não aceitar corrosão por Pitting em 20x de ampliação e perda de massa máxima em até $4 \mathrm{~g} / \mathrm{m}^{2}$ do corpo de prova. Constatouse que foi isento à corrosão por Pitting após as 24 horas de exposição do corpo de prova ao ensaio, tendo uma redução muito pequena de massa, sendo $132,5619 \mathrm{~g} \mathrm{o}$ peso do CP antes do ensaio e 132,5582 g após o término. Sendo assim, os resultados obtidos foram satisfatórios.

A tabela 7 apresenta os resultados do ensaio de corrosão conforme ASTM G48 método $A$.

\begin{tabular}{|c|c|c|c|c|c|c|}
\hline \multirow[b]{2}{*}{ Dimensões (mm) } & \multirow[b]{2}{*}{ Área $\left(m^{2}\right)$} & \multicolumn{2}{|c|}{ Massa (g) } & \multirow[b]{2}{*}{ Perda de Massa $\left(\mathrm{g} / \mathrm{m}^{2}\right)$} & \multirow[b]{2}{*}{ Pitting } & \multirow[b]{2}{*}{ Situação } \\
\hline & & $\begin{array}{c}\text { Antes do } \\
\text { Ensaio }\end{array}$ & $\begin{array}{c}\text { Após o } \\
\text { Ensaio }\end{array}$ & & & \\
\hline $14,3 \times 25,0 \times 48,0$ & 0,00452 & 132,5619 & 132,5582 & 0,82 & Isento & Aprovado \\
\hline
\end{tabular}

Tabela 7 - Ensaio de corrosão conforme ASTM G48 método A.

\section{CONCLUSÃO}

Os valores obtidos ratificaram que juntas soldadas de aços inoxidáveis duplex que apresentem frações volumétricas de ferrita e austenita próximas a $50 \%$ sem que 
haja a precipitação de fases deletérias, terão propriedades mecânicas e resistência à corrosão adequadas.

O ensaio de tração da junta soldada mostrou que a junta se rompeu no metal base e com um limite de resistência à tração mais de $20 \%$ superior ao definido como valor mínimo.

No ensaio de dobramento a amostra ficou isenta de descontinuidades.

O impacto Charpy teve aprovação da energia absorvida e expansão lateral com valores superiores a mais de duas vezes o mínimo estabelecido.

A análise micrográfica revelou que a amostra ficou isenta de fases deletérias e com uma matriz ferrítica-austenítica num percentual aceitável por norma.

A junta soldada apresentou resultado satisfatório no teste de corrosão por pitting conforme ASTM G48 método A.

Os resultados satisfatórios obtidos são resultado das boas práticas utilizadas na confecção da junta soldada, destacando-se o controle da temperatura interpasses abaixo de $150^{\circ} \mathrm{C}$ e o baixo aporte térmico utilizado em todos os passes durante a confecção da junta soldada.

\section{REFERÊNCIAS}

1) PADILHA, A. F.; Microestrutura e Propriedades. In: Materiais de Engenharia. São Paulo: Editora Hemus, Edição Eletrônica, vol. 1, 2000.

2) PADILHA, A. F.; PLAUT, R. L.; RIOS, P. R.; Stainless steel heat treatment: metallurgy and technologies. In: Totten, George E, ed.. Steel Heat Treatment Handbook. Boca Raton: Taylor \& Francis, 2007.

3) POHL, M.; PADILHA, A. F.; Aços inoxidáveis ferriticos-austeniticos com microestrutura duplex. Nickel, São Paulo, v.3, n.8, p.7, 1988.

4) RAMIREZ, L. A. J.; Estudo da Precipitação de Nitreto de Cromo e Fase Sigma por Simulação Térmica da Zona Afetada pelo Calor na Soldagem Multipasse de Aços inoxidáveis Duplex- Tese Mestrado - Escola Politécnica da USP - São Paulo, 1997, 176 pag.

5) ATAMERT, S.; KING, J. E.; Superduplex stainless steel - part 1, heat affected zone microstructure materials Sc. An Tech. v 8, n 10, pag. 896 - 911. 1992.

6) LIPPOLD, J. C. - Introduction to the Selection of Stainless Steels. ASM Metals Handbook, vol. 6 - Welding, Brasing and Soldering, 1993, p.1110 - 1111.

7) LIPPOLD, J. C.; NOBLE, D. N. - Selection of Wrought Duplex Stainless Steels. ASM Metals Handbook, vol. 6 - Welding, Brasing and Soldering, 1993, p.1111 - 1268.

8) LIPPOLD, J. C.; KOTECKI, D. J. - Welding Metallurgy and Weldability of Stainless Steels. Wiley-Interscience - A. John Wiley \& Sons, INC., Publication, 2005, p. 353.

9) VICENTE, A. A.; Pratica de Soldagem para aços Inoxidáveis Duplex, Departamento de Engenharia Metalúrgica e de Materiais, Escola Politécnica da USP, Universidade de São Paulo, 2013. Apostila de Aula.

10) CHARLES, J.; BERNHARDSSON, S.; Superduplex stainless steels: structure and properties. In: DUPLEX STAINLESS STEELS'91, Beaune, Proceedings. Ed: Charles, J.; Bernhardsson, S. Les Ulis, France, Les Éditions de physique, v.1, 1991

11) CHARLES, J.; CHEMELLE, P. - The history of duplex developments, nowadays DSS properties and duplex Market future trends. - 8th Duplex Stainless Steels conference, october/2010, Beaune, France, p.50. 
12) PARK, Y. H.; LEE, Z. H.; The Effect of Nitrogen and Heat Treatment on the Microstructure and Tensile Properties of $25 \mathrm{Cr}-7 \mathrm{Ni}-1.5 \mathrm{Mo}-3 \mathrm{~W}-\mathrm{xN}$ Duplex Stainless Steel Casting. Materials Science and Engineering A297, 2001.

13) GUNN, R. N.; (Ed.) Duplex Stainless Steels: Microstructure, properties and applications. Cambridge: Abington Publishing, 1997. 204p

14) LOPEZ, N.; CID, M.; PUIGGALI, M.; Influence of $\sigma$-Phase on Mechanical Properties and Corrosion Resistance of Duplex Stainless Steels, Corrosion Science, ํo 41, 1999.

15) ATAMERT, S.; KING, J. E.; Elemental partitioning and microestrutural development in duplex stainless steel weld metal. Acta Metal. Mater. v.39, n.3, p 273- 285, 1991.

16) CHARLES, J.; Super duplex stainless steels: structure and properties. In: Conference Duplex Stainless Steels '91, Beaune, France, 1991. Proceedings. France, 1991, p. 3-48.

17) ASME Boiler and Pressure Vessel Code IX/2010; Qualification Standard for welding and brazing procedure, welders, brazers, and welding and brazing operators. 18) ASTM G48-11(2015), Standard Test Methods for Pitting and Crevice Corrosion Resistance of Stainless Steels and Related Alloys by Use of Ferric Chloride Solution, ASTM International, West Conshohocken, PA, 2015.

19) Petróleo Brasileiro SA. - PETROBRAS. Norma N-133: Soldagem. REV. L, PETROBRAS, 2014.

20) Norsok Standard M601: Welding and Inspection of Piping, 5th ed. (Standards Norway, Lysaker, Norway, 2008). 